Article

\title{
Single Crystal Growth and Superconducting Properties of Antimony-Substituted $\mathrm{NdO}_{0.7} \mathrm{~F}_{0.3} \mathrm{BiS}_{2}$
}

\author{
Satoshi Demura ${ }^{1, *}$, Satoshi Otsuki ${ }^{1}$, Yuita Fujisawa ${ }^{1}$, Yoshihiko Takano ${ }^{2}$ and Hideaki Sakata ${ }^{1}$ \\ 1 Department of Physics, Tokyo University of Science, 1-3 Kagurazaka, Shinjuku-ku, Tokyo 162-8601, Japan; \\ cbe11451@outlook.com (S.O.); 1215702@ed.tus.ac.jp (Y.F.); sakata@rs.kagu.tus.ac.jp (H.S.) \\ 2 The World Premier International Center for Materials Nanoarchitectonics (WPI-MANA), National Institute \\ for Materials Science (NIMS), 1-2-1 Sengen, Tsukuba, Ibaraki 305-0047, Japan; takano.yoshihiko@nims.go.jp \\ * Correspondence: demura@rs.tus.ac.jp; Tel.: +81-3-3260-4271 (ext. 2223)
}

Received: 25 October 2017; Accepted: 19 December 2017; Published: 27 December 2017

\begin{abstract}
Antimony ( $\mathrm{Sb}$ ) substitution of less than $8 \%$ was examined on a single crystal of a layered superconductor $\mathrm{NdO}_{0.7} \mathrm{~F}_{0.3} \mathrm{BiS}_{2}$. The superconducting transition temperature of the substituted samples decreased as $\mathrm{Sb}$ concentration increased. A lattice constant along the $c$-axis showed a large decrease compared with that along the $a$-axis. Since in-plane chemical pressure monotonically decreased as $\mathrm{Sb}$ concentration increased, the suppression of the superconductivity is attributed to the decrease in the in-plane chemical pressure.
\end{abstract}

Keywords: $\mathrm{BiS}_{2}$-based superconductor; flux growth; layered structure; superconducting properties; magnetic susceptibility measurement; electrical resistivity measurement

\section{Introduction}

New layered $\mathrm{BiS}_{2}$-based superconductors $\mathrm{Bi}_{4} \mathrm{O}_{4} \mathrm{~S}_{3}$ and $\operatorname{Ln}(\mathrm{O}, \mathrm{F}) \mathrm{BiS}_{2}(\mathrm{Ln}=\mathrm{La}, \mathrm{Ce}, \mathrm{Pr}, \mathrm{Nd}, \mathrm{Sm}$, $\mathrm{Yb}$, and $\mathrm{Bi}$ ) have been reported [1-9]. Although a superconducting transition temperature $\left(T_{\mathrm{c}}\right)$ of $\operatorname{Ln}(\mathrm{O}, \mathrm{F}) \mathrm{BiS}_{2}$ is around $4 \mathrm{~K}, T_{\mathrm{c}}$ is increased when a lattice strain is introduced. One of the ways to introduce the lattice strain is by partial element substitution with a different ionic radius into $\mathrm{Ln}, \mathrm{Bi}$, or S site [10-16]. The strain introduced by partial element substitution in these crystals is the chemical pressure. For instance, when selenium (Se) is partially substituted with sulfur (S) in the superconducting layer in $\mathrm{La}(\mathrm{O}, \mathrm{F}) \mathrm{BiS}_{2}, T_{\mathrm{c}}$ and a superconducting volume fraction increase [10]. The substitution for a smaller lanthanide ion into the $L n$ site in the block layer also increases $T_{\mathrm{C}}[11-14]$. The increase in $T_{\mathrm{c}}$ by element substitution is correlated with the in-plane chemical pressure defined by Mizuguchi: $T_{\mathrm{C}}$ increases as in-plane chemical pressure increases [17]. The change in $T_{\mathrm{C}}$ by the element substitution of $L n$ or $S$ sites is attributed to the increase in in-plane chemical pressure. On the other hand, it is not known whether the change in $T_{\mathrm{c}}$ is understood in terms of in-plane chemical pressure when an element is partially substituted into the Bi site.

Here, we report on an examination of a substitution of antimony $(\mathrm{Sb})$ ions of less than $8 \%$ into $\mathrm{NdO}_{0.7} \mathrm{~F}_{0.3} \mathrm{BiS}_{2}$. Since the $\mathrm{Sb}$ ion has the same valence as that of the $\mathrm{Bi}$ ion, the effect of the chemical pressure can be investigated independently of the effect of the carrier concentration. We found that the lattice constant along the $c$-axis of $\mathrm{Sb}$-substituted samples decreased. Furthermore, superconductivity was suppressed by the $\mathrm{Sb}$ substitution. This suppression by $\mathrm{Sb}$ substitution can be explained by the change in the in-plane chemical pressure.

\section{Experimental Section}

$\mathrm{NdO}_{0.7} \mathrm{~F}_{0.3} \mathrm{Bi}_{1-x} \mathrm{Sb}_{x} \mathrm{~S}_{2}(x=0.01-0.08)$ single crystals were synthesized using a $\mathrm{CsCl} / \mathrm{KCl}$ flux method in an evacuated quartz tubes $[18,19]$. Powders of $\mathrm{Nd}_{2} \mathrm{~S}_{3}, \mathrm{Bi}_{2} \mathrm{O}_{3}, \mathrm{Bi}_{2} \mathrm{~S}_{3}, \mathrm{Sb}_{2} \mathrm{~S}_{3}$, and $\mathrm{BiF}_{3}$ with 
Bi grains were used as a starting material. The $\mathrm{Bi}_{2} \mathrm{~S}_{3}$ powders were prepared by reacting $\mathrm{Bi}$ and $\mathrm{S}$ grains in an evacuated quartz tube at $500{ }^{\circ} \mathrm{C}$ for $10 \mathrm{~h}$. A mixture of $0.8 \mathrm{~g}$ of starting material and $8 \mathrm{~g}$ of $\mathrm{CsCl} / \mathrm{KCl}$ powder was sealed in an evacuated quartz tube. The tube was heated at $800{ }^{\circ} \mathrm{C}$ for $10 \mathrm{~h}$, kept at $800{ }^{\circ} \mathrm{C}$ for $10 \mathrm{~h}$, and cooled down to $630{ }^{\circ} \mathrm{C}$ at the rate of $0.3{ }^{\circ} \mathrm{C} / \mathrm{h}$ or $1{ }^{\circ} \mathrm{C} / \mathrm{h}$. After this thermal process, the obtained material was washed by distilled water to remove the flux. $X$-ray diffraction (XRD) patterns using single crystal and powder samples were collected by a Rigaku $\mathrm{X}$-ray diffractometer (Rigaku, Tokyo, Japan) with $\mathrm{Cu} \mathrm{K} \alpha$ radiation using a $\theta-2 \theta$ method. These powder samples used in XRD measurements were prepared by grinding single crystals. Lattice constants along the $a$-and $c$-axes were determined using the $\theta-2 \theta$ technique. The surface condition of the single crystals was observed by a scanning electron microscope (SEM) (JEOL, Tokyo, Japan). The actual chemical composition was determined by an energy-dispersive X-ray (EDX) measurement (JEOL, Tokyo, Japan). Temperature dependence of the magnetic susceptibility down to $2 \mathrm{~K}$ was measured with the MPMS (magnetic property measurement system) (Quantum Design, San Diego, CA, USA). Temperature dependence of the electrical resistivity was measured down to $2.5 \mathrm{~K}$ with the four terminals method.

\section{Results}

Figure 1a shows $X$-ray diffraction patterns for $\mathrm{NdO}_{0.7} \mathrm{~F}_{0.3} \mathrm{Bi}_{1-x} \mathrm{Sb}_{x} \mathrm{~S}_{2}(x=0.01-0.08)$. All peaks correspond to the $(00 l)$ peaks of the $\mathrm{CeOBiS}_{2}$ type structure with the space group $\mathrm{P} 4 / \mathrm{nmm}$ symmetry. The (004) peaks of these samples are magnified in Figure 1b. The peaks are gradually shifted to the high angle side as the $\mathrm{Sb}$ concentration increased. This is indicative of success in $\mathrm{Sb}$ substitution into $\mathrm{NdO}_{0.7} \mathrm{~F}_{0.3} \mathrm{BiS}_{2}$ up to $x=0.08$. Figure $1 \mathrm{c}$ shows an $\mathrm{Sb}$ concentration dependence on the lattice constant along the $c$-axis. The lattice constant is almost constant up to $x=0.04$ and decreases when $x>0.04$. A lattice constant along the $a$-axis shows almost constant until $x=0.08$, as depicted in Figure $1 \mathrm{~d}$. The lattice shrinkage in the $c$-axis by $\mathrm{Sb}$ substitution was caused by the difference in ionic radius between the $\mathrm{Bi}$ and $\mathrm{Sb}$ ions, as we expected.

To evaluate sample quality, SEM and EDX measurements were performed in single crystals where $x=0.01$ and 0.08 , as shown in Figure 2. Figure 2a,b show SEM images of these obtained single crystals where $x=0.01$ and 0.08 , respectively. A square shape reflected from the tetragonal crystal structure can be seen. The shape did not change as the $\mathrm{Sb}$ concentration increased. In addition, the distribution of all elements included in the crystal was evaluated for the sample where $x=0.08$ in Figure $2 \mathrm{c}-\mathrm{h}$. All elements were homogeneously distributed in the sample. Therefore, the $\mathrm{Sb}$ ion was homogeneously substituted into the single crystal of $\mathrm{NdO}_{0.7} \mathrm{~F}_{0.3} \mathrm{BiS}_{2}$ until $x=0.08$. Furthermore, an actual $\mathrm{Sb}$ concentration was estimated for samples where $x=0.01$ and 0.08 . The actual $\mathrm{Sb}$ concentrations of the samples with a nominal composition of 0.01 and 0.08 were around 0.001 and 0.021 , respectively. The actual composition was quite lower than the nominal composition. Therefore, the actual $\mathrm{Sb}$ concentration increased until around 0.02 as nominal $\mathrm{Sb}$ concentration increased until 0.08 . Next, the superconducting properties of these samples were evaluated to investigate the effect of $\mathrm{Sb}$ substitution on superconductivity.

(a)

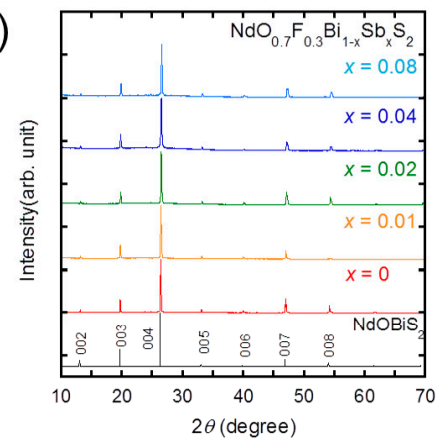

(b)

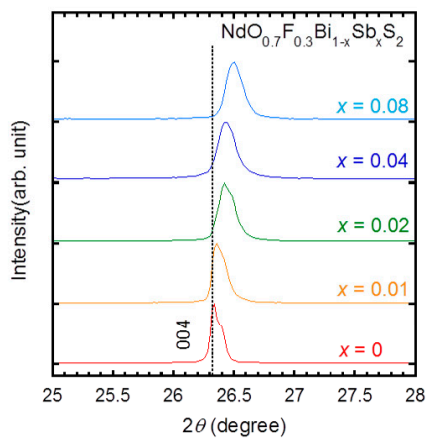

Figure 1. Cont. 

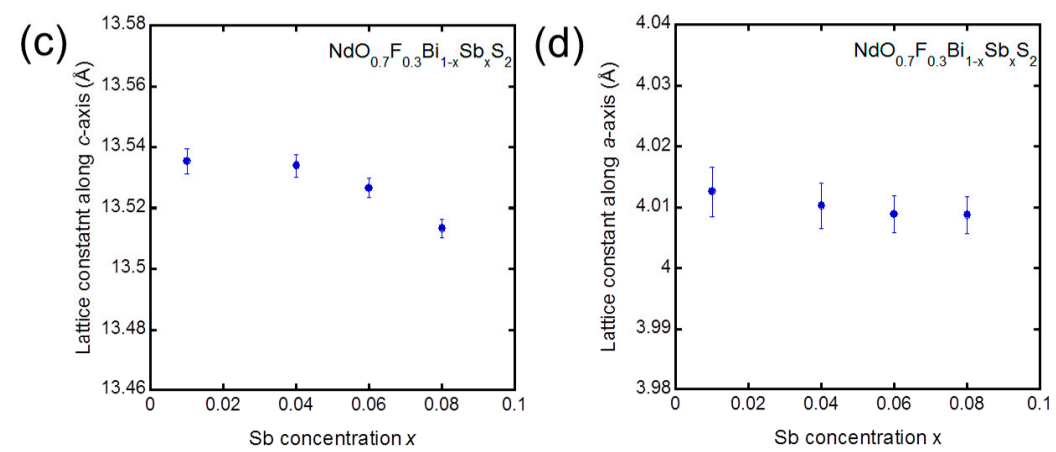

Figure 1. $\mathrm{XRD}$ patterns and lattice parameters of $\mathrm{NdO}_{0.7} \mathrm{~F}_{0.3} \mathrm{Bi}_{1-x} \mathrm{Sb}_{x} \mathrm{~S}_{2}$ single crystals. (a) XRD patterns from $x=0.01$ to 0.08 on the $\mathrm{NdO}_{0.7} \mathrm{~F}_{0.3} \mathrm{Bi}_{1-x} \mathrm{Sb}_{x} \mathrm{~S}_{2}$. (b) Magnified figure near the (004) peak in Figure 1a. (c,d) Lattice constants along the $c$ - and $a$-axes for $\mathrm{NdO}_{0.7} \mathrm{~F}_{0.3} \mathrm{Bi}_{1-x} \mathrm{Sb}_{x} \mathrm{~S}_{2}$.
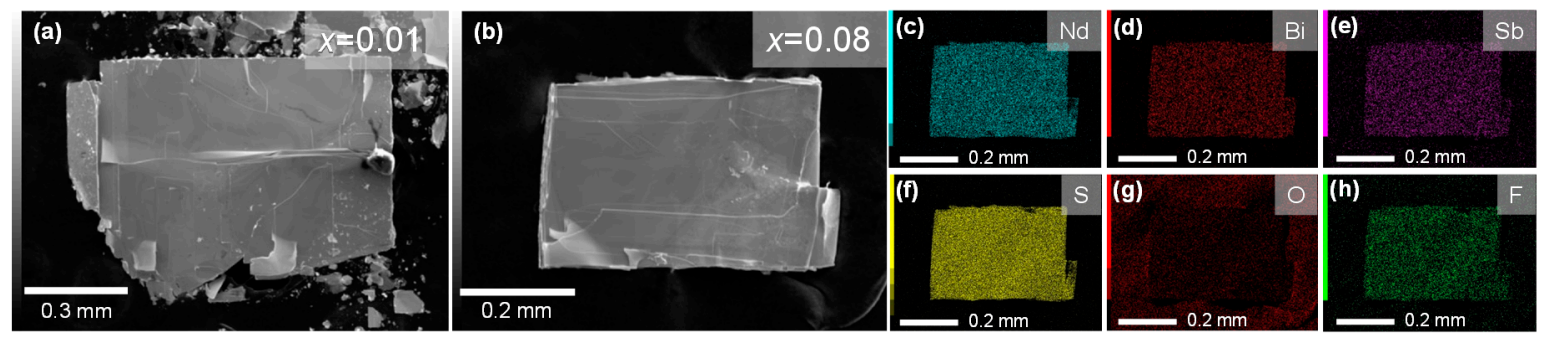

Figure 2. (a,b) SEM images of $\mathrm{NdO}_{0.7} \mathrm{~F}_{0.3} \mathrm{Bi}_{1-x} \mathrm{Sb}_{x} \mathrm{~S}_{2}$ single crystals $(x=0.01,0.08)$. (c-h) Mapping of the chemical composition of $\mathrm{Nd}, \mathrm{Bi}, \mathrm{Sb}, \mathrm{S}, \mathrm{O}$, and $\mathrm{F}$ for the single crystal of $\mathrm{NdO}_{0.7} \mathrm{~F}_{0.3} \mathrm{Bi}_{1-x} \mathrm{Sb}_{x} \mathrm{~S}_{2}$ $(x=0.08)$.

Figure $3 \mathrm{a}, \mathrm{b}$ show the magnetic susceptibility as a function of temperature for $\mathrm{NdO}_{0.7} \mathrm{~F}_{0.3} \mathrm{Bi}_{1-x} \mathrm{Sb}_{x} \mathrm{~S}_{2}(x=0.01-0.08)$ at a magnetic field of 10 Oe. All samples show diamagnetic signal due to an appearance of superconductivity. A magnitude of $4 \pi \chi$ decreases from 1 at $x=0.01$ to 0.2 at $x=0.08$. The superconducting transition temperature $\left(T_{\mathrm{c}}\right)$ monotonously decreases with increasing $\mathrm{Sb}$ concentration as shown in Figure $3 \mathrm{~b}$. In the zero field cooling process, all samples show a broad superconducting transition. This broad transition is often observed in the other $L n(\mathrm{O}, \mathrm{F}) \mathrm{BiCh}_{2}$ ( $\mathrm{Ln}=\mathrm{La}, \mathrm{Ce}, \mathrm{Pr}, \mathrm{Nd}, \mathrm{Ch}=\mathrm{S}$, Se) [20-24]. Although the reason why the transition is broadened is not yet understood, the broad transition seems to be a common feature in these materials.
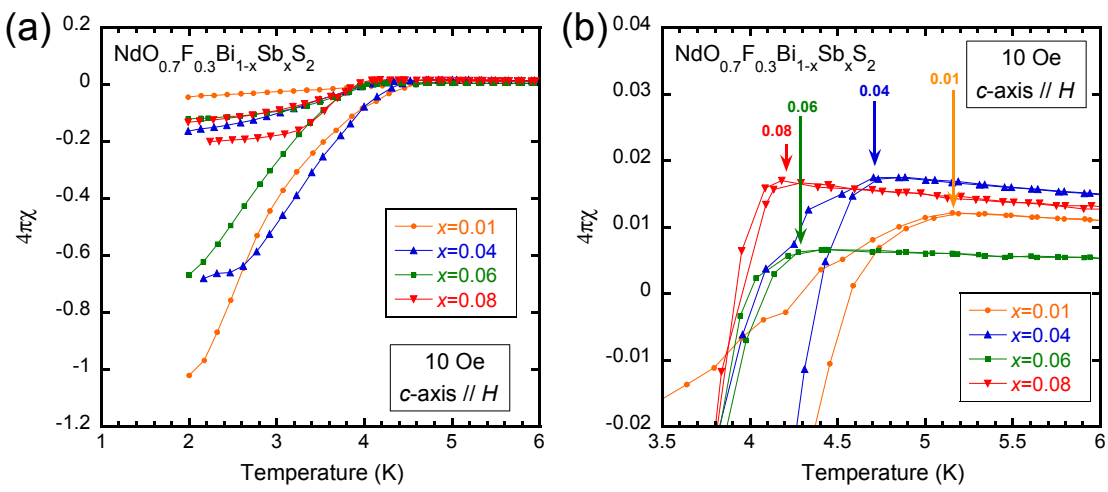

Figure 3. Magnetic susceptibility for $\mathrm{NdO}_{0.7} \mathrm{~F}_{0.3} \mathrm{Bi}_{1-x} \mathrm{Sb}_{x} \mathrm{~S}_{2}$ as a function of temperature. (a) Temperature dependence of magnetic susceptibility for $\mathrm{NdO}_{0.7} \mathrm{~F}_{0.3} \mathrm{Bi}_{1-x} \mathrm{Sb}_{x} \mathrm{~S}_{2}$ from 1 to $6 \mathrm{~K}$. (b) The magnetic susceptibility near the superconducting transition for $\mathrm{NdO}_{0.7} \mathrm{~F}_{0.3} \mathrm{Bi}_{1-x} \mathrm{Sb}_{x} \mathrm{~S}_{2}$. 
Figure $4 \mathrm{~b}$ shows the electrical resistivity near $T_{\mathrm{c}}$ as a function of temperature. A steep drop due to superconductivity can be observed at around $5.2 \mathrm{~K}$ in the sample where $x=0.01$. The transition temperature decreased as the $\mathrm{Sb}$ concentration increased. Resistivity at room temperature (RT) continuously increased as the Sb substitution increased, as shown in Figure 4a. This is because the $\mathrm{Sb}$ ion was substituted for the Bi ion located in the conduction layers. This increase in resistivity at RT has also been observed in Pb-substituted $\operatorname{Ln}(\mathrm{O}, \mathrm{F}) \mathrm{BiS}_{2}(\mathrm{Ln}=\mathrm{La}, \mathrm{Nd})[15,20]$, on the other hand $\mathrm{Pb}$ substitution induced an enhancement of $T_{\mathrm{c}}$. Therefore, the effect of substitution on superconductivity does not correlate to the strength of the scattering by the substituted atoms.
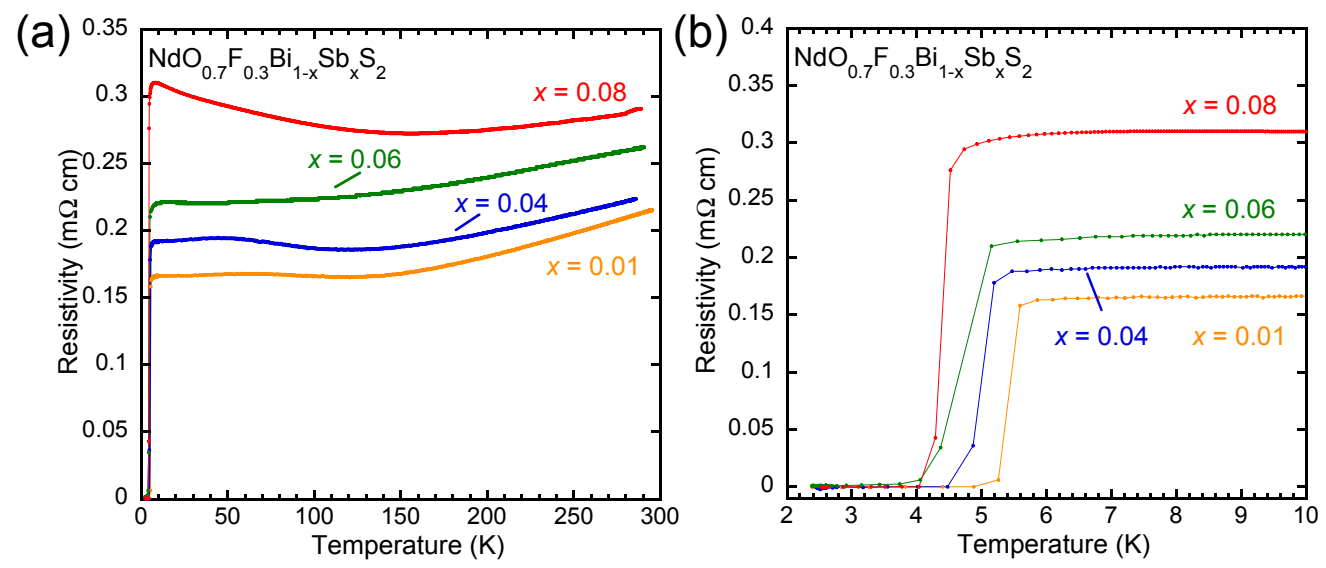

Figure 4. Temperature dependence of electrical resistivity for $\mathrm{NdO}_{0.7} \mathrm{~F}_{0.3} \mathrm{Bi}_{1-x} \mathrm{Sb}_{x} \mathrm{~S}_{2}$. (a) Temperature dependence of electrical resistivity for $\mathrm{NdO}_{0.7} \mathrm{~F}_{0.3} \mathrm{Bi}_{1-x} \mathrm{Sb}_{x} \mathrm{~S}_{2}(x=0.01-0.08)$ from 2 to $300 \mathrm{~K}$. (b) Temperature dependence of electrical resistivity for $\mathrm{NdO}_{0.7} \mathrm{~F}_{0.3} \mathrm{Bi}_{1-x} \mathrm{Sb}_{x} \mathrm{~S}_{2}(x=0.01-0.08)$ from 2 to $10 \mathrm{~K}$.

Figure $5 \mathrm{a}$ shows a summary of the observed $T_{\mathrm{c}}$. Here, $T_{\mathrm{C}}{ }^{\mathrm{mag}}$ is defined as the temperature at which magnetic susceptibility begins to decrease. $T_{\mathrm{c}}{ }^{\text {onset }}$ and $T_{\mathrm{c}}{ }^{\text {zero }}$ are defined as the temperature at which resistivity begins to decrease and the temperature where resistivity becomes zero, respectively. All $T_{\mathrm{c}}$ values monotonically decrease with an increase in $\mathrm{Sb}$ concentration.

Mizuguchi et al. reported that the $T_{\mathrm{c}}$ of $\mathrm{BiCh}_{2}$ superconductors is correlated with in-plane chemical pressure [17]. To compare the result in Sb-substituted samples with the previous report, we estimated the in-plane chemical pressure for $\mathrm{NdO}_{0.7} \mathrm{~F}_{0.3} \mathrm{Bi}_{1-x} \mathrm{Sb}_{x} \mathrm{~S}_{2}$. In-plane chemical pressure is defined by the ionic radius of the $\mathrm{Bi}$ and chalcogenide ions, as well as the distance between the $\mathrm{Bi}$ and chalcogenide ions located in the $\mathrm{BiCh}_{2}$ plane. In the case of $\mathrm{Sb}$ substitution, this in-plane chemical pressure is defined as follows:

in-plane chemical pressure $=\left((1-x) R_{\mathrm{Bi}}+x R_{\mathrm{Sb}}+R_{\mathrm{Ch}}\right) / \mathrm{Bi}-C h_{1}$ (in-plane) distance

where $R_{\mathrm{Bi}}$ is the ionic radius of the $\mathrm{Bi}$ ion. In this study, the ionic radius of the $\mathrm{Bi}$ ion was obtained from the structural data of the $\mathrm{LaO}_{0.77} \mathrm{~F}_{0.23} \mathrm{BiS}_{2}$ single crystal [25]. Thus, the value of $R_{\mathrm{Bi}}$ was $104.75 \mathrm{pm}$, which is almost the same value as that in the previous report [17]. $R_{\mathrm{Sb}}$ and $R_{\mathrm{Ch}}$ are the ionic radii of $\mathrm{Sb}^{3+}$ and $\mathrm{Ch}^{2-}$ ions, respectively. These values were determined as 76 and $184 \mathrm{pm}$, based on [26]. The composition of the $\mathrm{Sb}$ ion was used as the nominal value because this value in [17] was also calculated by using the nominal composition of the substituted ions. The $\mathrm{Bi}-\mathrm{Ch}_{1}$ distance in this study was estimated by the lattice constant along the $a$-axis. Since the lattice constant along the $a$-axis corresponds to the length of a side of the Bi square lattice, we used $1 / \sqrt{2}$ times the lattice constant along the $a$-axis as the $\mathrm{Bi}-\mathrm{Ch}_{1}$ distance. Figure $5 \mathrm{~b}$ shows the estimated in-plane chemical pressure dependence of $T_{\mathrm{C}}{ }^{\text {onset }}, T_{\mathrm{C}}{ }^{\mathrm{mag}}$, and $T_{\mathrm{C}}{ }^{\text {zero }}$, shown in open circles, filled circles, and squares, respectively. The $T_{\mathrm{c}}$ of all samples decreases with the decrease in in-plane chemical pressure. Based on this result, 
$T_{\mathrm{c}}$ in the Sb-substituted materials is positively correlated to the in-plane chemical pressure. To compare this result with the results with respect to $\mathrm{Ce}_{y} \mathrm{Nd}_{1-y} \mathrm{O}_{0.5} \mathrm{~F}_{0.5} \mathrm{BiS}_{2}$ and $\mathrm{Nd}_{y} \mathrm{Sm}_{1-y} \mathrm{O}_{0.5} \mathrm{~F}_{0.5} \mathrm{BiS}_{2}$ in [17], the $T_{c}$ of $\mathrm{Ce}_{y} \mathrm{Nd}_{1-y} \mathrm{O}_{0.5} \mathrm{~F}_{0.5} \mathrm{BiS}_{2}$ and $\mathrm{Nd}_{y} \mathrm{Sm}_{1-y} \mathrm{O}_{0.5} \mathrm{~F}_{0.5} \mathrm{BiS}_{2}$ are superimposed in Figure $5 \mathrm{~b}$, which are shown in filled triangles. The $T_{\mathrm{c}}$ in these materials shows a same change as our results against the in-plane chemical pressure. Thus, our result is qualitatively consistent with the previous results of [17]. In addition, these results suggest that the concept of in-plane chemical pressure is valid in the case of substitution not only at the $L n$ site in the blocking layer but also at the Bi site in the conduction layer.

In this study, the in-plane chemical pressure was estimated by the lattice constant along the $a$-axis. On the other hand, the in-plane chemical pressure in [17] was estimated by the Bi-Ch $\mathrm{C}_{1}$ distance, which was obtained from single crystal analysis. To compare the difference between these estimated in-plane chemical pressure values, both values were estimated using data from the single crystal analysis in [23]. In Figure $5 b$, the in-plane chemical pressure estimated by the $\mathrm{Bi}-\mathrm{Ch}_{1}$ distance is plotted as a triangle outline, while that estimated by the $a$-axis is plotted as an upside-down triangle. The latter, compared with the former, has a slightly higher value. However, since this value is located at the extrapolated line of the $T_{\mathrm{c}}$ of the Sb-substituted samples, this estimation can be used to estimate the in-plane chemical pressure qualitatively.

Finally, we compared this effect of $\mathrm{Sb}$ substitution with the effect of $\mathrm{Pb}$ substitution in $\mathrm{NdO}_{0.7} \mathrm{~F}_{0.3} \mathrm{BiS}_{2}$ because this $\mathrm{Pb}$ ion is expected to be substituted into the Bi site. Sb substitution suppresses superconductivity. This suppression is explained by the decrease in in-plane chemical pressure described in this paper. On the other hand, $\mathrm{Pb}$ substitution increased $T_{\mathrm{c}}$ to up to $6 \mathrm{~K}$. The in-plane chemical pressure of $\mathrm{Pb}$-substituted samples is almost constant because an ionic radius of the $\mathrm{Pb}^{2+}$ ion is almost the same as that of the $\mathrm{Bi}^{2.7+}$ ion calculated by the single crystal analysis. The ionic radius of the $\mathrm{Pb}^{2+}$ ion is $100 \mathrm{pm}$ [26]. If the $\mathrm{Pb}$ ion is substituted until $x=0.10, R_{\mathrm{Bi}}+R_{\mathrm{Pb}}$ is around $103.8 \mathrm{pm}$, which is almost the same value of the ionic radius of the $\mathrm{Bi}^{2.7+}$ ion of $104.75 \mathrm{pm}$. This indicates that the $T_{\mathrm{c}}$ of $\mathrm{Pb}$-substituted samples is independent of the value of the in-plane chemical pressure.
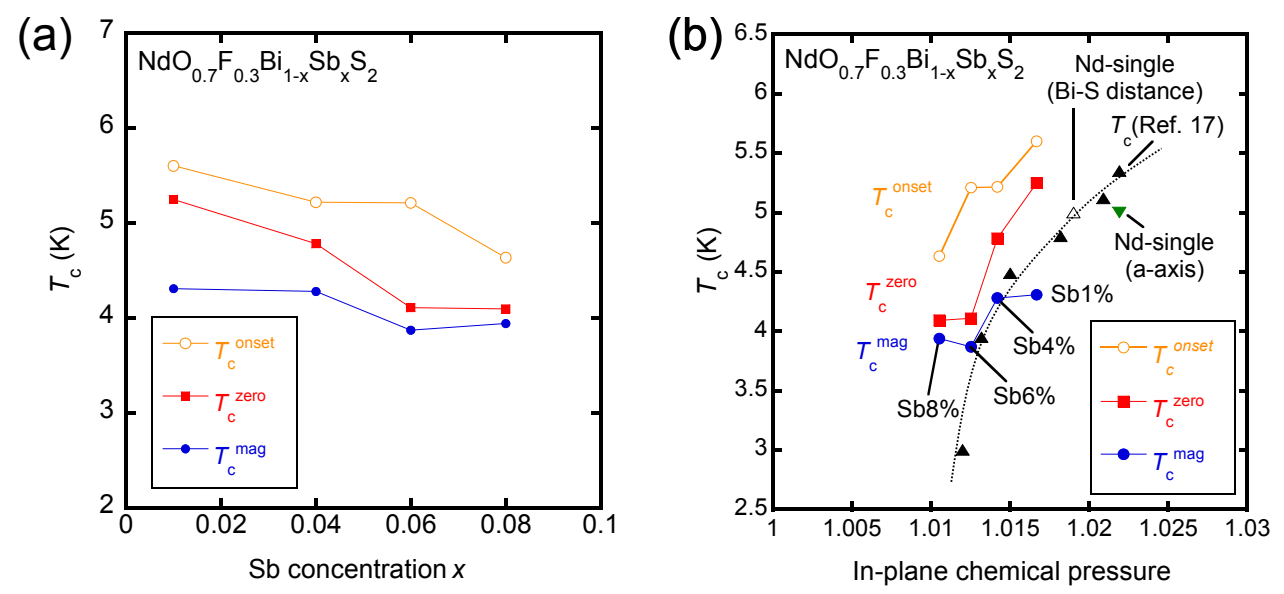

Figure 5. (a) Sb concentration $x$ dependence of $T_{\mathrm{c}}$ for $\mathrm{NdO}_{0.7} \mathrm{~F}_{0.3} \mathrm{Bi}_{1-x} \mathrm{Sb}_{x} \mathrm{~S}_{2}$. (b) Estimated in-plane chemical pressure dependence of $T_{\mathrm{c}}$ for $\mathrm{NdO}_{0.7} \mathrm{~F}_{0.3} \mathrm{Bi}_{1-x} \mathrm{Sb}_{x} \mathrm{~S}_{2}$. The $T_{\mathrm{c}}$ values of $(\mathrm{Ce}, \mathrm{Nd}) \mathrm{O}_{0.5} \mathrm{~F}_{0.5} \mathrm{BiS}_{2}$ and $(\mathrm{Nd}, \mathrm{Sm}) \mathrm{O}_{0.5} \mathrm{~F}_{0.5} \mathrm{BiS}_{2}$ are plotted as triangles, which were fitted by hand on the dotted line [18].

\section{Conclusions}

An examination of $\mathrm{Sb}$ substitution of less than $8 \%$ was performed with $\mathrm{NdO}_{0.7} \mathrm{~F}_{0.3} \mathrm{BiS}_{2}$. The $\mathrm{Sb}$ substitution caused a decrease in lattice constants along the $c$-axis, as well as a decrease in $T_{\mathrm{c}}$ and the superconducting volume fraction. The deterioration by these superconducting properties by the partial $\mathrm{Sb}$ substitution into the $\mathrm{Bi}$ site is explained in terms of the decrease in in-plane chemical pressure, indicating the utility of in-plane chemical pressure in $\mathrm{BiCh}_{2}$ superconductors. 
Acknowledgments: This work was partly supported by a Grant-in-Aid for Young Scientists (B) (No. 15K17710) and the Nanotech Career-up Alliance (Nanotech CUPAL).

Author Contributions: Satoshi Otsuki, Satoshi Demura and Hideaki Sakata conceived and designed the experiments; Satoshi Otsuki mainly performed the experiments; Satoshi Otsuki, Satoshi Demura and Yuita Fujisawa contributed the data analysis; Yoshihiko Takano contributed analysis tools; Satoshi Demura wrote the paper. All authors have read and approved the final manuscript.

Conflicts of Interest: The authors declare no conflict of interest.

\section{References}

1. Mizuguchi, Y.; Fujihisa, H.; Gotoh, Y.; Suzuki, K.; Usui, H.; Kuroki, K.; Demura, S.; Takano, Y.; Izawa, H.; Miura, O. $\mathrm{BiS}_{2}$-based layered superconductor $\mathrm{Bi}_{4} \mathrm{O}_{4} \mathrm{~S}_{3}$. Phys. Rev. B 2012, 86, 220510. [CrossRef]

2. Singh, S.K.; Kumar, A.; Gahtri, B.; Sharma, G.; Patnaik, S.; Awana, V.P.S. Bulk Superconductivity in Bismuth Oxysulfide $\mathrm{Bi}_{4} \mathrm{O}_{4} \mathrm{~S}_{3}$. J. Am. Chem. Soc. 2012, 134, 16504-16507. [CrossRef] [PubMed]

3. Mizuguchi, Y.; Demura, S.; Deguchi, K.; Takano, Y.; Fujihisa, H.; Gotoh, Y.; Izawa, H.; Miura, O. Superconductivity in Novel $\mathrm{BiS}_{2}$-Based Layered Superconductor $\mathrm{LaO}_{1-x} \mathrm{~F}_{x} \mathrm{BiS}_{2}$. J. Phys. Soc. Jpn. 2012, 81, 114725. [CrossRef]

4. Awana, V.P.S.; Kumar, A.; Jha, R.; Kumar Singh, S.; Pal, A.; Saha, S.J.; Patnaik, S. Appearance of superconductivity in layered $\mathrm{LaO}_{0.5} \mathrm{~F}_{0.5} \mathrm{BiS}_{2}$. Solid State Commun. 2013, 157, 21-23. [CrossRef]

5. Demura, S.; Mizuguchi, Y.; Deguchi, K.; Okazaki, H.; Hara, H.; Watanabe, T.; Denholme, S.J.; Fujioka, M.; Ozaki, T.; Fujihisa, H.; et al. New Member of $\mathrm{BiS}_{2}$-Based Superconductor $\mathrm{NdO}_{1-x} \mathrm{~F}_{x} \mathrm{BiS}_{2}$. J. Phys. Soc. Jpn. 2013, 82, 033708. [CrossRef]

6. Jha, R.; Kumar, A.; Singh, S.K.; Awana, V.P.S. Superconductivity at $5 \mathrm{~K}$ in $\mathrm{NdO}_{0.5} \mathrm{~F}_{0.5} \mathrm{BiS}_{2}$. J. Appl. Phys. 2013, 113, 056102. [CrossRef]

7. Xing, J.; Li, S.; Ding, X.; Yang, H.; Wen, H.-H. Superconductivity appears in the vicinity of semiconducting-like behavior in $\mathrm{CeO}_{1-x} \mathrm{~F}_{x} \mathrm{BiS}_{2}$. Phys. Rev. B 2012, 86, 214518. [CrossRef]

8. Jha, R.; Kumar, A.; Sngh, S.K.; Awana, V.P.S. Synthesis and Superconductivity of New $\mathrm{BiS}_{2} \mathrm{Based}^{-}$ Superconductor $\mathrm{PrO}_{0.5} \mathrm{~F}_{0.5} \mathrm{BiS}_{2}$. J. Supercond. Nov. Magn. 2013, 26, 499-502. [CrossRef]

9. Yazici, D.; Huang, K.; White, B.D.; Jeon, I.; Burnett, V.W.; Friedman, A.J.; Lum, I.K.; Nallaiyan, M.; Spagna, S.; Maple, M.B. Superconductivity induced by electron doping in $\mathrm{La}_{1-x} M_{x} \mathrm{OBiS}_{2}(M=\mathrm{Ti}, \mathrm{Zr}, \mathrm{Hf}, \mathrm{Th})$. Phys. Rev. $B$ 2013, 87, 174512. [CrossRef]

10. Hiroi, T.; Kajitani, J.; Omachi, A.; Miura, O.; Mizuguchi, Y. Evolution of Superconductivity in BiS 2 -Based Superconductor $\mathrm{LaO}_{0.5} \mathrm{~F}_{0.5} \mathrm{Bi}\left(\mathrm{S}_{1-x} \mathrm{Se}_{x}\right)_{2}$. J. Phys. Soc. Jpn. 2015, 84, 024723. [CrossRef]

11. Kajitani, J.; Omachi, A.; Hiroi, T.; Miura, O.; Mizuguchi, Y. Chemical pressure effect on $T_{\mathrm{c}}$ in $\mathrm{BiS}_{2}$-based $\mathrm{Ce}_{1-x} \mathrm{Nd}_{x} \mathrm{O}_{0.5} \mathrm{~F}_{0.5} \mathrm{BiS}_{2}$. Phys. C Supercond. Appl. 2014, 504, 33-35. [CrossRef]

12. Fang, Y.; Yazici, D.; White, B.D.; Maple, M.B. Enhancement of superconductivity in $\mathrm{La}_{1-x} \mathrm{Sm}_{x} \mathrm{O}_{0.5} \mathrm{~F}_{0.5} \mathrm{BiS}_{2}$. Phys. Rev. B 2015, 91, 064510. [CrossRef]

13. Yazici, D.; Jeon, I.; White, B.D.; Maple, M.B. Superconductivity in layered $\mathrm{BiS}_{2}$-based compounds. Phys. C Supercond. Appl. 2015, 514, 218-236. [CrossRef]

14. Fang, Y.; Wolowiec, C.T.; Yazici, D.; Maple, M.B. Chemical Substitution and High Pressure Effects on Superconductivity in the $\mathrm{LnOBiS}_{2}(\mathrm{Ln}=\mathrm{La}-\mathrm{Nd})$ System. Nov. Supercond. Mater. 2015, 1, 79-94. [CrossRef]

15. Demura, S.; Fujisawa, Y.; Otuski, S.; Ishio, R.; Takano, Y.; Sakata, H. Enhancement of $T_{\mathrm{c}}$ in BiS $\mathrm{B}_{2}$-based superconductors $\mathrm{NdO}_{0.7} \mathrm{~F}_{0.3} \mathrm{BiS}_{2}$ by substitution of $\mathrm{Pb}$ for Bi. Solid State Commun. 2015, 223, 40-44. [CrossRef]

16. Demura, S. Evolution of superconductivity and magnetism in $\mathrm{BiS}_{2}$-based layered compounds. Nov. Supercond. Mater. 2016, 2, 1-15. [CrossRef]

17. Mizuguchi, Y.; Miura, A.; Kajitani, J.; Hiroi, T.; Miura, O.; Tadanaga, K.; Kumada, N.; Magome, E.; Miriyoshi, C.; Kuroiwa, Y. In-plane chemical pressure essential for superconductivity in $\mathrm{BiCh}_{2}$-based (Ch: S, Se) layered structure. Sci. Rep. 2015, 5, 14968. [CrossRef] [PubMed]

18. Nagao, M.; Miura, A.; Demura, S.; Deguchi, K.; Watauchi, S.; Takei, T.; Takano, Y.; Kumada, N.; Tanaka, I. Growth and superconducting properties of F-substituted $\mathrm{ROBiS}_{2}(\mathrm{R}=\mathrm{La}, \mathrm{Ce}, \mathrm{Nd})$ single crystals. Solid State Commun. 2014, 178, 33-36. [CrossRef]

19. Nagao, $\mathrm{M}$. Growth and characterization of $\mathrm{R}(\mathrm{O}, \mathrm{F}) \mathrm{BiS}_{2}(\mathrm{R}=\mathrm{La}, \mathrm{Ce}, \mathrm{Pr}, \mathrm{Nd})$ superconducting single crystals. Nov. Supercond. Mater. 2015, 1, 64. [CrossRef] 
20. Otski, S.; Demura, S.; Sakai, Y.; Fujisawa, Y.; Sakata, H. Effect of Lead substitution on $\mathrm{LaO}_{0.5} \mathrm{~F}_{0.5} \mathrm{BiS}_{2}$. Solid State Commun. 2017, 270, 17-21. [CrossRef]

21. Miura, A.; Nagao, M.; Takei, T.; Watauchi, S.; Mizuguchi, Y.; Takano, Y.; Tanaka, I.; Kumada, N. Structure, Superconductivity, and Magnetism of $\mathrm{Ce}(\mathrm{O}, \mathrm{F}) \mathrm{BiS}_{2}$ Single Crystals. Cryst. Growth Des. 2015, 15, $39-44$. [CrossRef]

22. Nagao, M.; Miura, A.; Watauchi, S.; Takano, Y.; Tanaka, I. C-axis electrical resistivity of $\operatorname{PrO}_{1-a} \mathrm{~F}_{a} \mathrm{BiS}_{2}$ single crystals. Jpn. J. Appl. Phys. 2015, 54, 083101. [CrossRef]

23. Nagao, M.; Demura, S.; Deguchi, K.; Miura, A.; Watauchi, S.; Takei, T.; Takano, Y.; Kumada, N.; Tanaka, I. Structural Analysis and Superconducting Properties of F-Substituted $\mathrm{NdOBiS}_{2}$ Single Crystals. J. Phys. Soc. Jpn. 2013, 82, 113701. [CrossRef]

24. Tanaka, M.; Nagao, M.; Matsushita, Y.; Fujioka, M.; Denholme, S.J.; Yamaguchi, T.; Takeya, H.; Takano, Y. First single crystal growth and structural analysis of superconducting layered bismuth oxyselenide; $\mathrm{La}(\mathrm{O}, \mathrm{F}) \mathrm{BiSe}_{2}$. J. Solid State Chem. 2014, 219, 168-172. [CrossRef]

25. Miura, A.; Nagao, M.; Takei, T.; Watauchi, S.; Tanaka, I. Crystal structures of $\mathrm{LaO}_{1-x} \mathrm{~F}_{x} \mathrm{BiS}_{2}(\mathrm{x} \sim 0.23,0.46)$ : Effect of F doping on distortion of Bi-S plane. J. Solid State Chem. 2014, 212, 213-217. [CrossRef]

26. Jia, Y.Q. Crystal radii and effective ionic radii of the rare earth ions. J. Solid State Chem. 1991, 95, $184-187$. [CrossRef]

(C) 2017 by the authors. Licensee MDPI, Basel, Switzerland. This article is an open access article distributed under the terms and conditions of the Creative Commons Attribution (CC BY) license (http:/ / creativecommons.org/licenses/by/4.0/). 